\title{
RANJIVOST I OTPORNOST GRADOVA - NOVI ODGOVOR NA PRIRODNE KATASTROFE
}

\author{
Jasmina Gačić ${ }^{1}$, Slađana Babić ${ }^{2} \quad$ UDK=504.1:711.426 \\ https://doi.org/10.18485/fb_ubur.2018.1.ch17 \\ ${ }^{1}$ Fakultet bezbednosti, Univerzitet u Beogradu, jgacic@sezampro.rs \\ ${ }^{2}$ Fakultet bezbednosti, Univerzitet u Beogradu, sladjana.babic@fb.bg.ac.rs
}

\section{Sažetak}

Gradovi su se oduvek smatrali mestima društveno-ekonomskog napretka, urbane kulture i razvoja civilnog društva, odnosno inovativnim centrima i živim laboratorijama. Gradovi se često opisuju kao složeni i dinamični sistemi koji predstavljaju specifičnu mešavinu različitih naroda, s različitim kulturama, društvenim normama ponašanja i života te raznim važnim društvenim funkcijama. Zbog svega toga, oni predstavljaju ,destinacije globalizacije“ koje su prerasle lokalne okvire i zbog toga traže potpuno nov pristup razvoju i zaštiti. Svakako, može se reći da su svi gradovi ranjivi u odnosu na urbani prostor na koji mogu pozitivno, ali još više negativno uticati različiti ekonomski, socijalni i institucionalni faktori. Naime, danas više od polovine svetske populacije živi u gradovima, ili urbanim centrima.

Gradska naselja su žile kucavice društva. Ona predstavljaju motornu snagu nacionalne ekonomije, ona su centri tehnologije i prosperiteta, ona su živi dokaz naše kulturne zaostavštine. Gradovi preuzimaju različite uloge: kao centri političke moći, kako na nacionalnom, tako i na međunarodnom nivou, kao centri nacionalne i međunarodne trgovine, kao „kapije“ za svoje nacionalne države, a ponekad i za ceo region. Oni su centri bankarstva, osiguranja i finansijskih usluga, centri savremenih profesionalnih aktivnosti svih vrsta (na primer, medicine, prava ili visokog obrazovanja). Podjednako su i centri u koje stižu i iz kojih se diseminuju informacije, putem mas-medija ili štampe, ali i centri potrošnje, od luksuznih dobara do dobara za masovnu potrošnju, i centri umetnosti, kulture i zabave.

Istovremeno, gradovi mogu postati i generatori novih rizika: neuspele (kritične) infrastrukture i usluga, urbane degradacije životne sredine, širenja bespravne gradnje, gotovo milijarde stanovnika sirotinjskih kvartova širom sveta i, u novije vreme, koncentracije velikog broja izbeglica i prisilnih migranata. Sve ovo doprinosi tome da mnogi stanovnici urbanih sredina postaju izloženiji opasnostima i ranjivi na prirodne opasnosti. Za razliku od ranjivih gradova, otporni su gradovi oni u kojima se planiranjem i strategijama doprinosi razvoju neophodnih kapaciteta gradova da bi se uspešno suočili sa svim izazovima koje nosi budućnost.

Pored činjenice da je poboljšanje stanja ranjivih urbanih područja postao jedan od ključnih Milenijumskih razvojnih ciljeva, od izuzetnog je značaja da Međunarodna strategija Ujedinjenih nacija za smanjenje katastrofa (UNISDR) deluje zajedno sa svojim partnerima kako bi se podigla svest i posvećenost održivim razvojnim praksama koje će smanjiti rizik od 
katastrofa i povećati dobrobit i sigurnost građana - ulagati danas za bolje sutra. Nadovezujući se na prethodne kampanje s naglaskom na obrazovanje i bezbednost u školama i bolnicama, partneri UNISDR-a pokrenuli su novu kampanju u 2010. godini: „Učiniti gradove otpornima“. Ova međunarodna kampanja je nastojala da uveri gradske čelnike i lokalne vlade da se obavežu na Spisak od deset osnovica za grad otporan na katastrofe, kao i da rade zajedno s lokalnim aktivistima, društvenim mrežama i državnim vlastima. UNISDR je u saradnji sa partnerima razvio Spisak kao polazište za sve one koji se žele pridružiti kampanji.

Jednako je važna činjenica da je opredeljenje za ovih deset osnovica osnažilo lokalne samouprave i brojne agencije za sprovođenje Hjogo-okvira za delovanje 2005-2015: Izgradnja otpornosti država i zajednica na katastrofe, koji je 2005. godine usvojilo 168 vlada. Hjogo-okvir je imao određenih praznina koje je trebalo nadoknaditi, ali se ideja otpornosti ponovila u Sendai-okviru za smanjenje rizika od katastrofa kao: jačanje pripremljenosti za efikasan odgovor, oporavak, rehabilitaciju i rekonstrukciju u skladu sa filozofijom ,,izgradi ponovo bolje“ što sve zajedno jača otpornost na katastrofe.

Cilj rada je da se ukaže na činjenicu da uvođenje tema prirodnih katastrofa i otpornih gradova u domen politike predstavlja prvi, ali veoma značajan korak, jer je većina političkih lidera postala svesna rizika koje klimatske promene i prirodne katastrofe nose i potrebe da se na njih reaguje. Drugi korak i cilj rada jeste da ukaže na podjednako važnu činjenicu - da tema globalnih promena, koje obuhvataju i oblast prirodnih katastrofa, mora postati deo brige institucija i građana. Dobra urbanistička i lokalna uprava, kao institucionalni nivo najbliži građanima, ključ su za kreiranje takve otpornosti. Od suštinskog značaja je i uloga civilnog društva, planerâ i stručnjakâ u oblasti urbanizma iz različitih sektora, kao i društvenih grupa, da pomognu u razvoju inovativnih rešenja i da se uključe u aktivnosti lokalnih vlasti, kako bi se smanjila opasnost i podstakla dobra uprava kroz zajednički rad. Cilj ovog rada je i da prikupi relevantne naučne teze i rezultate istraživanja za podsticanje dalje rasprave o budućnosti gradova i uopšte o urbanoj budućnosti.

Rezultati rada bi trebalo da ukažu na činjenicu da gradovi koji proaktivno nastoje da smanje rizik od katastrofa, kroz aktivnosti održive urbanizacije, mogu imati veliku korist na brojne načine, a najvažniji su spaseni životi i imovina u slučaju katastrofe, uz dramatično umanjenje broja smrtnih slučajeva i psiho-socijalnih potreba. Ukoliko se uspešno primenjuje kao deo održive urbanizacije, tada koncept gradova otpornih na katastrofe pomaže u smanjenju siromaštva, osigurava rast i zapošljavanje, ali pruža i veću socijalnu pravdu, sveže poslovne mogućnosti, uravnoteženije ekosisteme, bolje zdravlje i poboljšano obrazovanje. Gradovi se moraju posvetiti ne samo sopstvenim nastojanjima da uspešno odgovore na stanje prirodnih katastrofa, već i poboljšanju odnosa sa susednim gradovima i regijama kako bi se uspostavili sistemi koji mogu pružiti pomoć jedni drugima u slučaju potrebe.

Ključne reči: grad, prirodne katastrofe, ranjivost, otpornost 


\section{Uvod}

Gradovi su se oduvek smatrali mestima društveno-ekonomskog napretka, urbane kulture i razvoja civilnog društva, odnosno inovativnim centrima i živim laboratorijama. Gradovi se često opisuju kao složeni i dinamični sistemi koji predstavljaju specifičnu mešavinu različitih naroda, s raznolikim kulturama, društvenim normama ponašanja i života te raznim važnim društvenim funkcijama. Zbog svega toga, oni predstavljaju „destinacije globalizacije“, koje su prerasle lokalne okvire i otuda iziskuju potpuno novi pristup razvoju i zaštiti.

Zanimljiva je analiza Luisa Mamforda, koji smatra da se grad u svom društvenom aspektu može opisati kao poseban okvir koji je usmeren na stvaranje i diferenciranje prilika za običan život i značajnu kolektivnu dramu. U poimanju grada važan je zaključak da su društvene činjenice primarne, a fizička organizacija grada, njegova industrija i trgovina, njegovi tokovi komunikacije i saobraćaja moraju biti podređeni društvenim potrebama. Iako smo u razvoju grada u poslednjih stotinu godina namerno proširili fizički plan i isto tako se odnosili prema osnovnom društvenom jezgru, organima uprave i obrazovanja, te društvenim uslugama, kao prema sporednim posledicama, danas se prema društvenom jezgru moramo odnositi kao prema esencijalnom elementu u svakom valjanom planu grada: lokacija i međusobni odnos škola, biblioteka, pozorišta, javnih centara treba da predstavljaju prvi zadatak u definisanju urbanog okruženja i postavljanju skica jednog integrisanog grada (Mamford, 2010).

Činjenica je da su gradovi podjednako značajni u pogledu bankarstva, osiguranja i finansijskih usluga, oni su centri savremenih profesionalnih aktivnosti svih vrsta (na primer, medicine, prava ili visokog obrazovanja). Istovremeno su i centri u koje stižu i iz kojih se diseminiraju informacije, putem mas-medija ili štampe, ali i centri potrošnje, od luksuznih dobara do dobara za masovnu potrošnju i centri umetnosti, kulture i zabave.

Gradovi su, dakle, izrazito kompleksni sistemi, satkani zajedno od hiljada ekonomskih, socijalnih, institucionalnih i ekoloških nítî koje utiču na individualno i društveno blagostanje. Danas više od 3 milijarde ljudi (polovina svetskog stanovništva) živi u urbanim sredinama. Ljudi se kreću u gradove u većem broju od bilo kojeg doba u istoriji, podstaknuti nadom u bolje mogućnosti ili potisnuti iz ruralnih područja usled siromaštva, degradacije životne sredine, konflikata ili stanja prirodnih katastrofa. Prirodni priraštaj je takođe bitan činilac koji doprinosi rastu urbane populacije i gustini naseljenosti.

Istraživanja pokazuju da u zemljama OECD-a, metropole obuhvataju samo 4\% zemljišta, ali imaju približno polovinu stanovništva i blizu 55\% BDP-a (OECD, 2015a). Pogodni ekonomski, socijalni i infrastrukturni elementi takođe su podstakli rast urbane populacije, sa manje od 1 milijarde 1950. na oko predskazanih 6 milijardi 2050. godine. U državama OECD-a stanovništvo u metropolitanskim područjima povećalo se za $12,5 \%$ u periodu od 2000. do 2014. godine. Rapidna urbanizacija je donela očigledan prosperitet i prilike za mnoge ljude.

Ovo je slučaj gde su gradovi dobro planirani i dobro vođeni, ukorak s potrebnom ekspanzijom infrastrukture i usluga. Gradovi i naselja u EU se, na primer, 
trenutno suočavaju s brojnim raznim izazovima i problemima. Dok se, s jedne strane, neki gradovi usled emigracije i starenja stanovništva suočavaju s padom broja stanovnika i problemima zbog prevelikog opsega sadašnjih kapaciteta, broj stanovnika u drugim gradovima raste, što povećava pritisak na postojeće kapacitete u tim gradovima i uzrokuje probleme poput nezaposlenosti (mladih), socijalne isključenosti, siromaštva, osiguravanja pristupačnog stanovanja, preopterećenosti prometa i zagađenja životne sredine. Sve je veći jaz između rastuće potražnje za lokalnim uslugama i stagnirajućim, odnosno sve manjim financijskim sredstvima. Istovremeno, gradovi u EU, ali i širom sveta, jesu i generatori novih rizika: neuspele (kritične) infrastrukture i usluga, urbane degradacije životne sredine, širenja bespravne gradnje, gotovo milijarde stanovnika sirotinjskih kvartova širom sveta, a u novije vreme i koncentracije velikog broja izbeglica i prisilnih migranata. Ovo ukupno doprinosi da mnogi stanovnici urbanih sredina postaju izloženiji antropogenim opasnostima od prirodnih opasnosti.

Za razliku od ranjivih gradova, otporni su gradovi oni u kojima se planiranjem i strategijama doprinosi razvoju neophodnih kapaciteta gradova da bi se uspešno suočili sa svim izazovima koje nosi budućnost. ${ }^{1}$

Pored činjenice da je poboljšanje stanja ranjivih urbanih područja postao jedan od ključnih Milenijumskih razvojnih ciljeva, od izuzetnog je značaja da Međunarodna strategija Ujedinjenih nacija za smanjenje katastrofa (UNISDR) deluje zajedno sa svojim partnerima kako bi se podigle svest i posvećenost održivim razvojnim praksama, koje će smanjiti rizik od katastrofa i povećati dobrobit i sigurnost građana - ulagati danas za bolje sutra. Nadovezujući se na prethodne kampanje s naglaskom na obrazovanje i bezbednost u školama i bolnicama, partneri UNISDR-a pokrenuli su novu kampanju u 2010. godini: „Učiniti gradove otpornima“. Ova međunarodna kampanja je nastojala da uveri gradske čelnike i lokalne vlade da se obavežu na Spisak od deset osnovica za grad otporan na katastrofe, kao i da rade zajedno s lokalnim aktivistima, društvenim mrežama i državnim vlastima. UNISDR je u saradnji sa partnerima razvio ovaj Spisak kao polazište za sve one koji se žele pridružiti kampanji.

Jednako je važna činjenica da je opredeljenje za ovih deset osnovica osnažilo lokalne samouprave i brojne agencije za sprovođenje Okvira Hjogo za delovanje 2005-2015: Izgradnja otpornosti država i zajednica na katastrofe, koji je 2005. godine usvojilo 168 vlada. Okvir Hjogo je imao određenih praznina koje je trebalo nadoknaditi, ali se ideja otpornosti ponovila u Okviru Sendai za smanjenje rizika od katastrofa kao: jačanje pripremljenosti za efikasan odgovor, oporavak, rehabilitaciju i rekonstrukciju u skladu sa koncepcijom ,izgradi ponovo bolje“, što sve zajedno jača otpornost na katastrofe.

1 Definicija se temelji na opisu otpornih gradova danom na mrežnoj stranici ResilientCity.org, koja predstavlja otvorenu i neprofitnu mrežu istraživača različitih struka čiji je cilj razviti kreativne, praktične i primenjive strategije koje će doprineti izgradnji kapaciteta u gradovima kako bi se uspešno suočili s problemima klimatskih promena, uništavanja okoline i nedostatka resursâ u uslovima globalnog rasta stanovništva u gradovima. 


\section{Ranjivost gradova}

Bez obzira na evidentne razlike u pristupu ranjivosti, od brojnih naučnih disciplina do različitih analitičara, ranjivost je uvek i prvenstveno orijentisana na fizičku i društvenu dimenziju zajednice. Ranjivost je stanje nezaštićenosti, koje zajednicu čini nemoćnom da se odupre onesposobljavajućim efektima događaja koji se najčešće posmatraju kao katastrofe ili prirodni hazardi (Mustafa, 1998). Ranjivost se može posmatrati kao saznanje da se neki građani suočavaju sa većim rizikom od povrede, smrću ili gubitkom imovine usled svojih društvenih i ekonomskih okolnosti (Phillips and Morrow, 2007).

U potrazi za novim pristupom ranjivosti Cardona zaključuje da ranjivost potiče od a) fizičke slabosti ili izloženosti, odnosno podložnosti šire i uže društvene zajednice da bude pogođena opasnom pojavom zbog svoje lokacije; b) društvenoekonomske slabosti, koja podrazumeva relativne slabosti i nedostatke kakvi u društveno-ekonomskom smislu obeležavaju zajednicu; c) nedostatka elastičnosti (otpornosti), koji je izražen kroz nesposobnost i ograničenje društva da mobilizuje postojeće kapacitete (Cardona, 2004). Ranjivost se menja tokom vremena i zavisi od fizičkih, društvenih, ekonomskih faktora i faktora životne sredine. Mur smatra da su gradovi najkompleksnije ljudske kreacije, ali su pod istovremenim rizikom od širokog spektra opasnosti, a to implicira njihovu višestruku ranjivost. Kao što je napomenuo, tačke urbane ranjivosti su svuda u infrastrukturnom sistemu: zgrade za telekomunikacije, transport i energiju, kao i linije za snabdevanje resursima. Smanjenje ugroženosti i ranjivosti u gradskim sredinama nije samo stvar jačanja infrastruktura. Urbani mehanizmi za smanjenje rizika uključuju policijske i vatrogasne snage, planiranje i odeljenja za inspekciju zgrada, zdravstvene službe, porodice, škole i medije (Moor, 2001).

Poslednjih decenija je ranjivost u pogledu prirodnih opasnosti ponovo preuzela primat u odnosu na tehnološke ili druge opasnosti koje ugrožavaju zajednicu. Prema podacima iz Međunarodne baze podataka o nesrećama OFDA/CRED (EMDAT), širom sveta je porastao broj prirodnih katastrofa. U deceniji 1900-1909. godine prirodne katastrofe su se desile 73 puta, ali je u periodu 2000-2005. broj pojava porastao na 2.788 . Takođe, podaci iz navedene baze podataka pokazuju da su u periodu 1994-2013. zabeležene 6.873 prirodne opasnosti širom sveta, koje su odnele 1,35 miliona ljudskih života, što je u proseku 68.000 života godišnje (CRED, 2015).

Ujedno je pokazano da je učestalost pojavljivanja geofizičkih opasnosti (zemljotresa, vulkanskih erupcija, klizišta, cunamija) ostala ujednačena, dok je zabeležen porast pojavljivanja hidrološko-meteoroloških opasnosti (poplave, oluje pojava ekstremnih temperatura, suše...). U kombinaciji s uticajem ekstremnih klimatskih događaja i rastućim siromaštvom - čak milijarda ljudi danas živi u siromašnim gradskim četvrtima i u ekstremnom siromaštvu - povećana gustina naseljenosti gradova, takođe, predstavlja novi problem. Sve više ljudi naseljava se u potencijalno opasnim zonama, kao što su područja zemljotresa, ravnice podložne bujicama i priobalna područja. Oni su tako postupili jer odgovorni za urbanističko planiranje i vlade nisu pružili alternative, pa ti ljudi ne mogu sebi da priušte bez- 
bednije okruženje. Prirodne opasnosti moraju da budu od velike važnosti za urbaniste, prostorne planere i gradsku upravu.

Prirodne opasnosti utiču na gradove na različite načine, ali i je izražen potencijal za katastrofu, s obzirom na to da se gradske vlasti suočavaju s prenaseljenošću, rapidnom urbanizacijom i degradacijom životne sredine. Tako na primer, zemljotresi utiču na gradove, jer mnogi gusto izgrađeni i naseljeni gradovi leže na pojasevima seizmičkih aktivnosti. Loše projektovane zgrade koje nisu u skladu sa principima aseizmičkog projektovanja ili loše održavane zgrade ne mogu izdržati silu seizmičkih šokova, pa je veća verovatnost rušenja. Većina smrtnih slučajeva usled potresa dogodila se zbog urušavanja zgrada.

Rastući broj nekvalitetno izgrađenih, ili improvizovanih domova koji su izgrađeni na padinama ili ispod strmih padina, na liticama ili na rečnim ušćima u planinskim dolinama, u kombinaciji s lošom drenažom ili zaštitom od nagiba, rezultuje time da je sve više ljudi izloženo katastrofalnim klizištima. Adekvatna gradnja, sistem ranog upozoravanja, obaveštavanja i uzbunjivanja te planovi evakuacije predstavljaju primarne mere za rešavanje ovog problema. Urbana područja su izložena ciklonima, snažnim vetrovima i obilnim kišama. Primarne mere su gradnja otporna na vetar, sistem ranog upozoravanja sa savetima za domaćinstva da zatvore prozore i zaštite imovinu, te, ako je potrebno, i evakuacija.

Izlivanje velikih reka i bujične poplave najčešći su i najopasniji rizici u većini gradova širom sveta, pri čemu statistički podaci pokazuju da $40 \%$ od svih prirodnih katastrofa obuhvataju upravo poplave. Bujice predstavljaju rastuću opasnost za gradove, jer su šume previše eksploatisane i uništene kao vezivno tkivo, beton i zbijeno tlo ne upijaju vodu, otvoreni prostori su naseljeni, zbog gradnje preusmereni su rečni tokovi, jer gradski odvodni sistemi nisu adekvatni. Suša je takođe elementarna opasnost $\mathrm{u}$ porastu, koja nastaje sporo i izaziva migracije u urbana područja, čime se stvara dodatni pritisak na stambenu politiku, zapošljavanje i osnovne usluge.

Navedene karakteristike prirodnih opasnosti ukazuju na činjenicu da, bez obzira na to koliko je zemlja dobro pripremljena i koliko su solidni okviri njenih politika, ona će se često suočavati sa katastrofama, uz neizbežne i veoma razorne posledice. Ako su procesi oporavka samo delimično sprovedeni i nisu usmereni na jačanje otpornosti, posledice katastrofa mogu trajati veoma dugo i uticati na živote čitavih generacija.

\section{Nova dimenzija otpornosti}

Otpornost (rezilijentnost) jeste široko rasprostranjen koncept i koriste ga brojne institucije, akademska zajednica, državni i međunarodni organi zaduženi za sprečavanje katastrofa. Postoji mnogo primena ovog koncepta, posebno u društvenim naukama, ali ne uvek sa čvrstim teorijskom bazom. Raznolikost značenja rezilijentnosti može se objasniti višestrukom upotrebom različitih disciplina, gde svaka doprinosi različitom značenju koncepta. 
Koncept otpornosti u urbanom kontekstu bio je pozajmljen iz studija o načinu na koji se ekološki sistemi suočavaju sa poremećajima izazvanih spoljašnjim faktorima (Davič \& Velški, 2004). Iz ekološke perspektive, Holling (1973) sugeriše da je otpornost „upornost/istrajnost odnosa unutar sistema“ i „sposobnost ovih sistema da apsorbuju promene promenljivih stanja, ali da parametri i dalje postoje“ (Holling, 1973: 17). Drugim rečima, otpornost je ,sposobnost sistema da se podvrgne/izloži poremećajima i održava svoje funkcije i kontrolu“ (Gunderson \& Holling, 2001).

Rasprostiranje koncepta otpornosti kao načina razmišljanja u interdisciplinarnim naučnim pristupima ističe svojstvo otpornosti kao ,sposobnost ljudskih zajednica da izdrže spoljne šokove u svojoj socijalnoj infrastrukturi i da se oporave od takvih poremećaja“ (Adger, 2000). Šokovi i pritisci se odnose na varijabilnosti životne sredine (klimatski ekstremi, najezde štetočina, epidemije, prirodne katastrofe, smanjivanje raspoloživih prirodnih resursa), kao i na promene socijalne sredine (ekonomski i politički preokreti, kao što su brze promene na svetskim tržištima ili migracionim tokovima, turizam, razvoj infrastrukture, socijalno-prostorne transformacije, ekonomske krize i neizvesnost, zdravstveni rizici).

Otpornost najšire može biti definisana kao „sposobnost sistema, zajednice ili društva izloženog riziku da se odupre, apsorbuje, prilagodi i oporavi od efekata rizika na blagovremen i delotvoran način, uključujući i očuvanje i obnovu najvažnijih osnovnih struktura i funkcija“ (UNISDR, 2009). Otuda komponente otpornosti uključuju sposobnost društvenog sistema da uči, da razmatra raspoložive opcije i postupa fleksibilno (Schipper \& Langston, 2015). Razvijena svest o mogućim rizicima i sposobnost učenja iz događaja sa neželjenim posledicama čine važne elemente pripremljenosti i oporavka. Tako se unapređuje fleksibilnost društvenog sistema, koja pomaže da se podnese šok i izbegne kolaps, da se efekti katastrofe svedu na najmanju moguću meru i da se ostvari brz oporavak (Mayunga, 2007).

Otporan grad je održiva mreža fizičkih sistema i ljudske zajednice. Fizički sistemi su konstruisani tako da obuhvataju i prirodne komponente, odnosno životnu sredinu grada. To uključuje njihove puteve, zgrade, infrastrukturu, komunikacije, energiju, objekte, vodene tokove, zemljište, topografiju, geologiju i druge prirodne sisteme. Ukratko, fizički sistemi deluju kao telo grada, sklop njegovih kostiju, arterija i mišića. Za vreme katastrofa fizički sistemi moraju biti u mogućnosti da prežive i funkcionišu pod ekstremnim stresom. Ako ih dovoljno oštećujemo, gubici eskaliraju i usporava se oporavak. Grad bez elastičnih fizičkih sistema biće izuzetno ugrožene katastrofe (Godschalk, 1999).

S druge strane, ljudske zajednice su socijalne i institucionalne komponente grada. One uključuju formalna i neformalna, stalna i ad hoc ljudska udruženja koja posluju u urbanim sredinama: škole, agencije, organizacije, preduzeća, kontingente radne snage i slične asocijacije. Ukratko, zajednice deluju kao mozak grada, usmeravajući svoje aktivnosti i odgovarajući na svoje potrebe. Tokom katastrofe, mreže zajednice moraju biti u mogućnosti da prežive i funkcionišu u ekstremnim i jedinstvenim uslovima. Ako se razbiju, donošenje odluka će biti otežano. 
Socijalne i institucionalne mreže pokazuju različit stepen organizacije, identiteta i kohezije. Kao što inženjeri analiziraju krhkost fizičkih struktura pod stresom, tako društvene nauke razvijaju krive krhkosti za organizacije pod pritiskom (Zimmerman, 2001). Jednako tako, grad bez elastičnih zajednica biće izuzetno podložan katastrofama. Tradicionalni programi za ublažavanje opasnosti usredsređeni su na izradu fizičkih sistema otpornosti na sile katastrofa. Ovo je razumljivo, jer su neposredne povrede i oštećenja rezultat njihovog neuspeha.

Gejs smatra da se budući programi ublažavanja takođe moraju biti usredsređeni na proces učenja društvenih zajednica i institucija grada da smanji rizike $i$ efikasno reaguju na katastrofe jer one su najodgovornije za izgradnju urbanističke elastičnosti (Geis, 2000). On je takođe naglasio potrebu za holističkim i integrisanim pristupom koja se bavi vezama i odnosima, a ne samo strukturnim integritetom zgrada. Mnogi savremeni autori koriste termin „fleksibilnost“ kako bi ukazali na orijentaciju na povezivanje fizičkih i društvenih sistema (Olshansky \& Kartez 1998). Rezilijentnost i ranjivost su koncepti koje su naučnici razvili da objasne relacije, recipročne efekte i povratne informacije između ljudskih i prirodnih sistema (Gotham \& Campanella, 2011).

\section{Deset osnova za grad otporan na katastrofe}

Imajući u vidu da se međunarodna zajednica sve češće suočava sa prirodnim opasnostima i da su one postale povećana briga za odgovorne osobe koje se bave prostornim planiranjem, urbanim i održivim razvojem, pokrenuta je Međunarodna kampanja „Učinimo gradove otpornima: Moj grad se priprema“. Međunarodna kampanja predlaže spisak od Deset osnova za grad otporan na katastrofe, koje mogu da sprovedu gradonačelnici i lokalne uprave. Ovaj spisak nastao je iz pet prioriteta Okvira Hyogo za delovanje 2005-2015: Izgradnja otpornosti država i zajednica na katastrofe, ključnog instrumenta za sprovođenje akcija smanjenja rizika od katastrofa. Postizanje svih ili pak nekih od deset osnova pomoći će gradovima da postanu otporniji:

1) Uspostaviti organizaciju i koordinaciju, kako bi se smanjio rizik od katastrofa, utemeljenu na učestvovanju građanskih udruženja i civilnog društva. Graditi lokalne saveze. Osigurati da svi nadležni organi razumeju svoju ulogu u smanjenju rizika od katastrofa i stvaranju pripravnosti na ove rizike.

2) Odrediti proračun za smanjenje rizika od katastrofa i pružiti podsticaj vlasnicima kuća, porodicama s niskim primanjima, zajednicama, preduzećima i javnom sektoru da investiraju u smanjenje rizika s kojim se suočavaju.

3) Održavati ažurirane podatke o opasnosti i izloženosti, pripremiti procenu rizika i koristiti je kao temelj za urbanističke planove i odluke. Osigurati dostupnost ovih informacija i planova javnosti, omogućiti javnosti da raspravlja o njima.

4) Investirati u, i održavati, kritičnu infrastrukturu koja smanjuje rizik, kao što je kanalizacijski sistem u slučaju bujica, a koja je po potrebi prilagođena kako bi se nosila s klimatskim promenama. 
5) Proceniti sigurnost svih škola i zdravstvenih ustanova, poboljšati ih i nadograditi prema potrebi.

6) Primeniti i sprovoditi realne, s rizikom usklađene propise o gradnji i načela prostornog planiranja. Identifikovati bezbedan prostor za građane s niskim primanjima i razviti sistem poboljšanja i nadogradnje.

7) Osigurati da škole i lokalne zajednice usvoje programe za obrazovanje i programe obuka o smanjenju rizika od katastrofa.

8) Zaštititi ekosisteme i prirodne barijere za ublažavanje bujica, olujnih udara i drugih opasnosti kojima vaš grad može biti izložen. Prilagoditi se klimatskim promenama, oslanjajući se na dobre prakse smanjenja rizika.

9) Uvesti sistem ranog upozoravanja i kapacitete upravljanja vanrednim (kriznim) situacijama u određenom gradu, kao i održavati redovne javne vežbe pripravnosti.

10) Nakon bilo koje katastrofe osigurati da su potrebe preživelih i centri aktivnosti obnovljeni i rekonstruisani, kroz pružanje podrške njima i njihovim zajednicama u osmišljavanju i sprovođenju mehanizama, ekonomski rast i zapošljavanje, jer sigurniji i dobro vođeni gradovi privlače više investicija.

Uprkos pozitivnim rezultatima, Okvir Hjogo pokazao je i izvesne nedostatke, pre svega na polju prevencije i u multisektorskom pristupu u rešavanju problema prirodnih katastrofa. Iz tih razloga, Okvir iz Sendaja usvojen je 2015. kao dokument koji bi trebalo da zameni Okvir za delovanje iz Hjogoa (2005-2015): izgradnja otpornosti zemalja i zajednica na katastrofe (UNISDR, 2005).

Glavni cilj koncepta smanjenja rizika od katastrofa iz Okvira iz Sendaja jeste izgradnja otpornosti na prirodne i antropogene opasnosti kroz identifikovanje i efikasno upravljanje rizicima, a ne samo kroz upravljanje katastrofama (UNISDR, 2015). Okvir iz Sendaja zasniva se na elementima koji su ustanovljeni u Okviru za delovanje iz Hjogoa, ali u njemu su dodatno naglašene adaptivne i transformativne sposobnosti zajednica koje treba da im omoguće prevazilaženje stresova i šokova, i oporavak za „građenje boljeg nego što je bilo“. Okvir iz Sendaja naglašava smanjenje rizika od katastrofa i otpornost kao ključne elemente za ostvarivanje održivog humanog razvoja (UNISDR, 2016).

U julu 2016. Evropska komisija usvojila je Akcioni plan za implementaciju Okvira iz Sendaja u evropskim politikama za smanjenje rizika od katastrofa (European Commission, 2016). Akcioni plan uključuje glavne prioritete iz Okvira iz Sendaja prilagođene potrebama Evropskog okvira politika za smanjenje rizika od katastrofa. Akcioni plan naglašava značaj uključivanja lokalnih vlasti, civilnog društva i zajednica u razvoj konkretnih strategija za razvijanje svesti o riziku radi uključivanja najranjivijih grupa u datom okruženju.

Međunarodna kampanja predlaže spisak predloga šta možete učiniti kako bi vaš grad bio otporniji:

- Udruženja lokalnih vlada: 1) Stavite smanjenje rizika od katastrofa na vrh vašeg dnevnog reda. 2) Postanite partner UNISDR-a kako biste preneli poruku vašim lokalnim upravama. 3) Podržite sprovođenje kampanje na nivoima lokalne vlasti i lokalne zajednice. 
- Državne vlade: 1) Uspostavite i podstaknite državne platforme za smanjenje rizika od katastrofa, koje je podržalo više interesnih grupa, a koje uključuju i lokalne vlade, ili njihova udruženja. 2) Razmotrite pitanja lokalne uprave i održivog urbanizma. 3) Pobrinite se da vaša ministarstva i institucije razmotre pitanje smanjenja rizika prilikom izrade planova i politika. 4) Podstaknite ekonomski razvoj u ruralnim područjima i manjim gradovima u cilju smanjenja pritiska sve veće migracije stanovništva u visokorizična rubna područja i sirotinjske četvrti. 5) Učinite da smanjenje rizika od katastrofa postane državni i lokalni prioritet, jasno identifikujte institucionalne odgovornosti za smanjenje rizika na svim nivoima.

- Građanska udruženja: 1) Prijavite se za kampanju i podstaknite vašu organizaciju na učestvovanje. 2) Promovišite aktivno učestvovanje članova zajednice u kampanji, putem promotivnih i informativnih resursa kampanje. 3) Izgradite partnerstva kroz projekte s lokalnom vladom, nevladinim organizacijama, privatnim sektorom kako biste vaše okruženje učinili sigurnijim. 4) Podelite vaša znanja i iskustva s ostalim akterima, podržite aktivnosti kao što su planiranje, procena i mapiranje rizika, održavanje kritične infrastrukture, sigurnije prostorno planiranje i sprovođenje standarda gradnje. 5) Sarađujte u merenju napretka kroz participativni monitoring.

- UN, međunarodne ili regionalne organizacije, nevladine organizacije: 1) Prijavite se kao partner kampanje i obavežite se za podršku lokalnim vlastima u izgradnji otpornosti na katastrofe. 2) Nastojte da razvijete bolje alate i metodologije za smanjenje rizika u urbanim sredinama u bilo kojoj oblasti u Deset osnova za grad otporan na katastrofe. 3) Zalažite se za efikasnije smanjenje rizika u urbanim sredinama na lokalnom nivou. 4) Podstaknite veću uključenost lokalnih aktera $\mathrm{u}$ razvoju regionalne i međunarodne politike. 5) Ojačajte veze između nevladinih organizacija, jedinica lokalne samouprave i građanskih organizacija.

Cilj ove kampanje bio je da se istaknu najbolje prakse i uspesi gradova kroz njihova iskustva u nastojanjima da smanje rizike od prirodnih katastrofa. Dobri primeri su nekada najbolji način da se uključe svi ostali zainteresovani. Kampanja je trebalo da pokaže šta je moguće učiniti, kao i pokazati koristi od oblikovanja grada otpornog na rizike kojima su izložene urbane sredine.

\section{Zaključak}

Uvođenje tema prirodnih katastrofa, ranjivih i otpornih gradova u domen politike predstavlja prvi, ali veoma značajan korak, jer je većina političkih lidera postala svesna rizika koje nose klimatske promene i prirodne katastrofe i potrebe da se na njih reaguje. Neophodno je takođe da se ukaže na podjednako važnu činjenicu - da tema globalnih promena koje obuhvataju i oblast prirodnih katastrofa mora da postane deo brige institucija i građana. Dobra urbanistička i lokalna uprava, kao institucionalni nivo najbliži građanima, ključ je za kreiranje takve otpornosti. Od suštinskog značaja je i uloga civilnog društva, planera i stručnjaka u oblasti urbani- 
zma iz različitih sektora, kao i društvenih grupa, da pomognu u razvoju inovativnih rešenja i da se uključe u aktivnosti lokalnih vlasti, kako bi se smanjila opasnost $i$ podstakla dobra uprava kroz zajednički rad.

Gradovi koji proaktivno nastoje da smanje rizik od katastrofa, kroz aktivnosti održive urbanizacije, mogu na brojne načine imati veliku korist, a najvažniji su spaseni životi i imovina u slučaju katastrofe, uz dramatično smanjenje broja smrtnih slučajeva i psiho-socijalnih potreba. Ukoliko se uspešno primenjuje kao deo održive urbanizacije, tada koncept gradova otpornih na katastrofe pomaže u smanjenju siromaštva, osiguravaju rast i zapošljavanje, ali pružaju i veću socijalnu pravdu, sveže poslovne mogućnosti, uravnoteženije ekosisteme, bolje zdravlje i poboljšano obrazovanje. Gradovi se moraju posvetiti ne samo sopstvenim nastojanjima da uspešno odgovore na stanje prirodnih katastrofa, već i poboljšanju odnosa sa susednim gradovima i regijama kako bi se uspostavili sistemi koji mogu pružiti pomoć jedni drugima u slučaju potrebe.

\section{Literatura}

1. Adger, N. (2000). Social and ecological resilience: are they related?. Progress in Human Geography, 24 (3), 347-364.

2. Allman, L., Fleming, P., Wallace, A. (2004). The progress of English and Welsh local authorities in addressing climate change. Local Environmental, 9, 271-283.

3. Bulkeley, H. (2010). Cities and the governing of climate change. Annual Review of Environment and Resources, 35, 229-253.

4. Cardona, O. (2004). The Need for Rethinking the Concept of Vulnerability and Risk from a Holistic Perspective: A Necessary Review and Criticism for Effective Risk Management, in: Bankoff, Georg, Hilhorst, Dorothea (Eds.), Mapping Vulnerability, Disasters, Development \& People. London-Sterling, Va.: Earthscan, 37-51.

5. Davic, D., Welsh, H. (2004). On the ecological roles of salamanders. Annual Review of Ecology, Evolution, and Systematics, 35, 405-434.

6. Folke, C., Jansson, A., Rockström, J., Olsson, P., Carpenter, S. R., Chapin, F. S., Crépin, A.S., et al. (2011). Reconnecting to the biosphere. AMBIO: A Journal of the Human Environment, 40 (7), 719-738.

7. Geis, D. E. (2000). 'By design: The disaster-resistant and quality-of-life community. Nat. Hazards Rev., 1(3), 151-160.

8. Godschalk, D. R. (2003). Urban hazards mitigation: Creating resilient cities. Natural Hazards Review, 4 (3), 136-143.

9. Godschalk, D. R., Beatley, T., Berke, P., Brower, D. J., and Kaiser, E. J. (1999). Natural hazard mitigation: Recasting disaster policy and planning. Island Press, Washington, D.C.

10. Gotham, K., Campanella, R. (2011). Coupled vulnerability and resilience: the dynamics of cross-scale interactions in post-Katrina New Orleans. Ecology and Society, 16(3), 12. http://dx.doi.org/10.5751/ES-04292-160312.

11. Gunderson, L., Holling, C. S. (Eds.). (2001). Panarchy: Understanding transformations in human and natural systems. Washington (DC): Island Press.

12. Holling, C. (1973). Resilience and stability of ecological systems. Annual review of ecology and systematics, 4, 1-23. 
13. Mamford, L. (2010). Kultura gradova. Novi Sad: Mediterran Publishing.

14. Mayunga, J. (2007). Understanding and Applying the Concept of Community Disaster Resilience: A Capital-based Approach. A draft working paper prepared for the summer academy for social vulnerability and resilience building, 22-28 July, Munich.

15. Moor, J. (2001). Cities at risk. Habitat Debate, 7(4), 1-6.

16. Mustafa, D. (1998). Structural causes of vulnerability to food hazard in Pakistan. Economic Geography, 74 (3), 289-305.

17. OECD (2015a). The Metropolitan Century: Understanding Urbanisation and its Consequences, Paris: OECD Publishing.

18. Olshansky, R. B., Kartez, J. D. (1998). Managing land use to build resilience. Cooperating with nature: Confronting natural hazards with land-use planning for sustainable communities, R. Burby, ed., Joseph Henry Press, Washington, D.C., 167201.

19. Phillips, D. Morrow, H. (2007). Social science research needs: focus on vulnerable populations, forecasting, and warnings. Natural Hazards Review, 8 (3), 61-80.

20. Schipper, F. L, L. Langston. (2015). A Comparative Overview of Resilience Measurement Frameworks: Analysing Indicators and Approaches. Working Paper 422. London, ODI.

21. Sendai Framework for Disaster Risk Reduction 2015-2030. Geneva, UNISDR. www.preventionweb.net/files/43291_sendaiframeworkfordrren.pdf, UNISDR, International Strategy for Disaster Reduction (2010). Making cities resilient: My city is getting ready, 2010-2011.

22. UNISDR - UN International Strategy for Disaster Reduction (2010). Making cities resilient: My city is getting ready, 2010-2011. World Disaster Reduction Campaign.

23. Zimmerman, R. (2001). Resiliency, vulnerability, and criticality of human systems. Research theme from the New York University Workshop on Learning from Urban Disasters, http://www.nyu.edu/icis/Recovery/projects.html\&.

\section{VULNERABILITY AND RESILIENCE OF CITIES - A NEW RESPONSE TO NATURAL DISASTERS}

\section{Summary}

Cities have always been considered places of socio-economic development, urban culture and civil society development, or rather innovation centres and living labs. Cities are often described as complex dynamical systems which represent a specific mix of different people with different cultures, social norms of behaviour and lifestyles as well as of various important social functions. Consequently, they represent "destinations of globalization" that have outgrown local boundaries and therefore are looking for a completely new approach to the development and protection. Certainly, it can be said that all cities are vulnerable in relation to the urban space which can be positively or even more often negatively affected by different economic, social and institutional factors. In fact, today more than half of the world's population live in cities or urban centres. Urban settlements are the lifeline of society. 
They are the engine of the national economy, they are centres of technology and prosperity, they are living proof of our cultural heritage. Cities take different roles: as centres of political power, both at national and international level, as centres of national and international trade, as a "gate" for their own national state, and sometimes for the whole region. They are centres of banking, insurance and financial services, centres of modern professional activities of all kinds (such as medicine, law or higher education). They are equally the centres which gather and disseminate information through the mass media or the press, or centres of consumption of both luxury goods and goods for mass consumption, centres of arts, culture and entertainment.

At the same time, cities can also become generators of new risks: failed (critical) infrastructure and services, urban environmental degradation, the spread of illegal constructions, almost a billion slum dwellers worldwide, and in recent times the concentration of large numbers of refugees and forced migrants. All this contributes to the fact that many urban residents are becoming more exposed to risk from natural hazards. Unlike vulnerable cities, resilient cities are those where the planning and strategies contribute to the development of the necessary capacity of cities to successfully face all the challenges of the future.

Apart from the fact that the improvement of the situation of vulnerable urban areas has become one of the key Millennium Development Goals, it is essential that the United Nations International Strategy for Disaster Reduction (UNISDR) should work together with its partners to raise awareness and commitment to sustainable development practices that will reduce the risk of disasters and increase well-being and safety of citizens - to invest today for a better tomorrow. Building on the previous campaigns focusing on education and safety at schools and hospitals, the UNISDR partners launched a new campaign in 2010: "Making Cities Resilient." This international campaign has been trying to convince city leaders and local governments to commit themselves to the list of ten essentials for the city resilient to disasters and to work together with local activists, social networks and national authorities. UNISDR in collaboration with partners developed this list as a starting point for those who want to join the campaign. Equally important is the fact that the commitment to these ten essentials empower local governments and various agencies for the implementation of the Hyogo Framework for Action 2005-2015: Building the Resilience of Nations and Communities to Disasters, which in 2005 was adopted by 168 governments. Hyogo Framework had some gaps that needed to be recovered, but the idea of resilience was reiterated in the Sendai Framework for Disaster Risk Reduction as: enhancing preparedness for effective response, recovery, rehabilitation and reconstruction in accordance with the philosophy of "Build Back Better," all of which strengthens resilience to disasters.

The aim is to highlight the fact that the introduction of the topic of natural disasters and resilient cities in the political arena is the first but very important step, because most political leaders became aware of the risks that climate change and natural disasters bring and the need for them to react. The second step and the aim of this paper is to point out equally important fact - that the issue of global changes which include the area of natural disasters must become a part of the care by institutions and citizens. Good urban and local governance, as the institutional level closest to citizens, are the key to creating such resilience. Of crucial importance is also the role of civil society, planners and experts in urban planning from different sectors and social groups, to assist in the development of innovative 
solutions and to engage in the activities of local authorities, in order to reduce risk and encourage good governance through community work. Another aim of this paper is to collect relevant scientific theses and research findings to stimulate further discussion on the future of cities and the urban future in general.

The results of this paper should point to the fact that cities which proactively seek to reduce the risk of disasters, through the activities of sustainable urbanization can have great benefit in many ways, the most important being saved lives and property in the event of a disaster with a dramatic reduction in the number of deaths and psychosocial needs. If successfully implemented as part of sustainable urbanization, then the concept of cities resilient to disasters helps to reduce poverty, provides for growth and employment, but also provides greater social justice, fresh business opportunities, balanced ecosystems, better health and improved education. Cities must commit not only to their own efforts to effectively respond to the state of natural disaster, but also to improve relations with neighbouring cities and regions to establish systems which can provide assistance to each other in case of need.

Keywords: city, natural disasters, vulnerability, resilience 